\section{Examining reliability and multicollinearity of scale items}

\author{
WILLIAM M. HOLMES \\ Sociology Department \\ Case Western Reserve University \\ Cleveland, Ohio 44106
}

When data for a set of scale items have been gathered, the researcher may debate whether to combine items into a scale or use the items separately. Items from a highly reliable scale will generally be too multicollinear to use separately in a regression analysis (Bartlett, 1950; Rockwell, 1975). Items from a scale having mediocre reliability might provide more information if used separately in the analysis than if combined into a scale (Bohrnstedt, 1969), provided they are not too multicollinear. The program described here examines both the reliability and multicollinearity of scale items, so the researcher can make an informed judgment of tradeoffs involved in scaling or using the items separately.

Input. The program requires the following information: number of items or variables, sample size, FORTRAN format of a square correlation matrix of the items, and the correlation matrix of the items.

Output. Example output is provided in Table 1. A printout of the correlations, number of items, and sample size is provided to allow checking for mistakes in the input.

Scale reliability is examined by computing alpha reliability for the items using Bohrnstedt's (1969) procedure, which works directly from a correlation matrix of the items. In addition, the average correlation for all items (called MATRIX AVERAGE COR in the program), as well as the average correlation of each item with all other items (ITEM AVERAGE COR in the program), is computed. The multiple correlation of each item with all other items is also provided. The matrix average correlation can be used in estimating omega reliability (Allen, 1974), since it approximates the

Table 1

Example Output

COR MATRIX ANALYZER

\section{INPUT CORS}

\begin{tabular}{|c|c|c|c|c|}
\hline $\begin{array}{r}1.00 \\
.49 \\
.53 \\
.39\end{array}$ & $\begin{array}{r}.49 \\
1.00 \\
.61 \\
.51\end{array}$ & $\begin{array}{r}.53 \\
.61 \\
1.00 \\
.80\end{array}$ & $\begin{array}{r}.39 \\
.51 \\
.80 \\
1.00\end{array}$ & \\
\hline ALPHA $=$ & .83302 & \multicolumn{2}{|c|}{4 VARIABLES } & 280 CASES \\
\hline \multicolumn{3}{|c|}{$\begin{array}{l}\text { MATRIX AVERAGE COR= } \\
\text { ITEM AVERAGE CORS }\end{array}$} & .55500 & \\
\hline \multicolumn{5}{|c|}{$\begin{array}{l}.47 \\
\text { MULTIPLE CORS }\end{array}$} \\
\hline .54 & .63 & .81 & .68 & \\
\hline DET $=$ & $.151221 \mathrm{CHI}=$ & & $45.42 \mathrm{DF}=$ & 6 \\
\hline
\end{tabular}

average squared factor loading. The multiple correlation of each item with all other items indicates whether some items should be deleted from the scale. In addition, their squares can be used as starting estimates of communalities for factor scaling.

Scale item multicollinearity is examined using a chi-square test developed by Bartlett (1950), Farrar and Glauber (1967), Haitovsky (1969), and Rockwell (1975). This is a test of the null hypothesis that the determinant of the correlation matrix is equal to 1.0 . Under complete independence of the items, the determinant of the correlation matrix is 1.0 ; under complete multicollinearity, it equals 0 . The test statistic (CHI) is distributed approximately as chi-square, with degrees of freedom equal to $p(p-1)$, where $p$ is the number of items. If the source of the multicollinearity lies with a single item, this will be revealed by having a higher multiple correlation than any other item.

Hardware. The program was developed on a UNIVAC 1108 computer using CHI/OS, but it is designed to be compatable with the IBM 360 . Approximately $39 \mathrm{~K}$ bytes are required for core. Execution time averages 1 to $7 \mathrm{sec}$, depending on the number of items.

Language. The program is written in FORTRAN V. The choice of commands was designed to be compatable with FORTRAN IV and should be portable to most FORTRAN compilers. The correlation matrix is dimensioned as a 16 by 16 matrix. The program assumes a function is available for computing the determinant of the correlation matrix, although a copy of such a function routine is available upon request.

Availability. A source listing and sample output of the program is available without charge from William Holmes, Sociology Department, Case Western Reserve University, Cleveland, Ohio 44106. An instruction sheet describing use of the program is also available.

\section{REFERENCES}

Allen, M. P. Construction of composite measures by the canonical factor regression method. In $\mathrm{H}$. Costner (Ed.), Sociological methodology 1973-74. San Francisco: Josey-Bass, 1974.

Bartletr, M. S. Tests of significance in factor analysis. British Journal of Psychology, Statistical Section, 1950, 3, 77-85.

BoHRNSTEDT, G. A quick method for determining the reliability and validity of a multiple item scale. American Sociological Review, 1969, 34, 542-548.

FarRar, D., \& Glauber, R. Multicollinearity in regression analysis. Review of Economics and Statistics, 1967, 49, 92-107.

Haitovsky, Y. Multicollinearity in regression analysis: A comment. Review of Economics and Statistics, 1969, 51, 486-489.

Rocxwell, R. C. Assessment of multicollinearity: The Haitovsky test of the determinant. Sociological Methods and Research, 1975, 3, 308-320.

(Accepted for publication November 3, 1978.) 